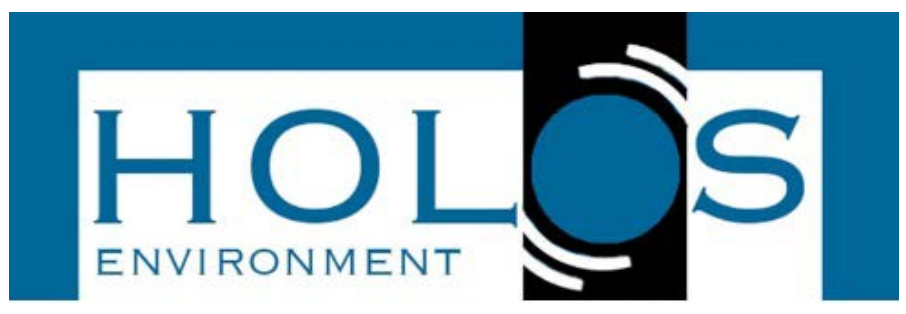

\title{
EMPREGO DO SISTEMA DE LODO ATIVADO PARA TRATAMENTO DE EFLUENTES DA INDÚSTRIA DE CONSERVA DE COGUMELOS
}

\section{USE OF THE ACTIVATED SLUDGE SYSTEM FOR TREATMENT OF EFFLUENTS FROM THE MUSHROOM PICKLE INDUSTRY}

\author{
Diego Macedo Veneu ${ }^{1}$, Bruna Camargo Rocha ${ }^{1}$, Cristiane Ribeiro Mauad ${ }^{2}$, Jonas dos \\ Santos Pacheco ${ }^{1}$, Cristiani Hertel ${ }^{1}$,
}

Artigo recebido em: 02/07/2017 e aceito para publicação em: 13/03/2018.

DOI: http://dx.doi.org/10.14295/holos.v18i1.12178

Resumo: Neste trabalho foi avaliado o tratamento de um efluente de conserva de cogumelos através do processo de lodos ativados em sistema contínuo. Foram avaliadas as variáveis respostas DQO, turbidez e $\mathrm{pH}$, além do monitoramento da concentração de SST no reator. Nos primeiros 12 dias de operação houve uma forte variação de DQO no efluente final obtendo remoções < $90 \%$, após este período, as remoções aumentaram, atingindo remoções $>97 \%$. Os valores obtidos de SST no reator aproximam-se mais da variante lodos ativados convencional apresentando do $6^{\circ}$ dia ao $24^{\circ}$ dia de operação, os valores na faixa de 2198 a $3620 \mathrm{mg} \mathrm{L}^{-1}$. Os percentuais de remoção de turbidez praticamente mantiveram-se na faixa de $50 \mathrm{a} 82 \%$. Os valores de $\mathrm{pH}$ inicial (entrada no reator) no início do processo de lodos ativados variaram entre os valores de 2,9 a 5,2. Já os valores de pH final, ou seja, na saída do decantador secundário mantiveram-se na faixa de 6,8 a 8,0, muito próximo da faixa recomendada de operação.

Palavras-chave: Tratamento de efluentes. Lodos ativados. Indústria de conserva.

Abstract: In this work, the treatment of a mushroom pickle effluent through the process of activated sludge in a continuous system was evaluated. The variables COD, turbidity and $\mathrm{pH}$ responses were evaluated, as well as the monitoring of the TSS concentration in the reactor. In the first 12 days of operation there was a strong COD variation in the final effluent, obtaining removals $<90 \%$, after this period, the removals increased, reaching removals $>97 \%$. The values obtained from TSS in the reactor are closer to the conventional activated sludge variant, presenting values from 2198 to $3620 \mathrm{mg} \mathrm{L}^{-1}$ from the 6th day to the 24th day of operation. The percentages of turbidity removal practically remained in the range of 50 to $82 \%$. The initial $\mathrm{pH}$ values (reactor input) at the beginning of the activated sludge process ranged from 2.9 to 5.2. However, the final pH values, that is, at the outlet of the secondary settler, remained in the range of 6.8 to 8.0 , very close to the recommended range of operation.

Keywords: Wastewater treatment. Sludge activated. Canning industry.

\footnotetext{
${ }^{1}$ Universidade Severino Sombra (USS), Vassouras, RJ. Emails: (diegomveneu@yahoo.com.br, brunacamargo2011@live.com, pachecojonas@yahoo.com.br, cristiani hertel@hotmail.com)

1 Instituto Federal de Educação, Ciência e Tecnologia do Rio de Janeiro (IFRJ), Rio de Janeiro, RJ. Email: (crisrmauad@gmail.com)
} 


\section{INTRODUÇÃO}

Segundo Giordano (2004) a utilização de água pela indústria pode ocorrer de muitas formas diferentes, entre elas estão: incorporação ao produto; lavagens de máquinas, tubulações e pisos; águas de sistemas de resfriamento e geradores de vapor; nestes casos todas as águas utilizadas diretamente nas etapas do processo industrial ou incorporadas aos produtos; e também os esgotos sanitários de toda a indústria tornam-se contaminadas dando assim origem aos chamados efluentes industriais.

No Brasil, como em outros países em desenvolvimentos, os tratamentos de efluentes líquidos industriais tem sido um tema muito discutido, principalmente no que diz respeito às questões legais, que estabelecem padrões máximos de lançamento no corpo receptor através do aparato legal federal (Resolução Conama 430), estadual (DZ-205 e NT-202) e em alguns casos municipais (Brasil, 2011 ; Inea, 1994 ; Inea, 1986). Depois de avaliar a legislação vigente, o segundo passo é estabelecer o arranjo da Estação de Tratamento de Efluente (ETE) que tem como objetivo garantir que o mesmo já tratado, atinja os padrões de lançamento estabelecidos.

O sistema de lodos ativados é amplamente utilizado, a nível mundial, para o tratamento de efluentes industriais, em situações que são necessários uma elevada qualidade de efluente e reduzidos requisitos de área (Von Sperling, 2005). No estudo do modelo dos sistemas de lodos ativados, alguns parâmetros operacionais são constantemente investigados para se obter a máxima eficiência na remoção de poluentes. Segundo Van Haandel e Marais (1999), estes parâmetros de projetos são baseados na idade do lodo $\left(\Theta_{c}\right)$, relação alimento/microrganismo $(A / M)$, tempo de detenção hidráulica (TDH), sólidos suspensos totais (SST) e voláteis (SSV), dentre outros.

Este trabalho tem como objetivo o tratamento de um efluente de conserva de cogumelos, através do processo de lodos ativados em sistema contínuo durante 24 dias, avaliando as principais variáveis que atuam no processo através dos resultados de DQO, turbidez, SST e pH ao longo do tempo. 


\section{MATERIAL E MÉTODOS}

\subsection{Descrição da Empresa e das Etapas do Processo}

A Empresa localizada no município de Engenheiro Paulo de Frontin/RJ atua na área alimentícia, cultivando cogumelos para serem vendidos em conserva. Dispõe de um galpão administrativo e outro onde ocorre o processo de produção, que contempla a etapa de: (i) cultivo dos cogumelos, (ii) envase e (iii) estocagem.

\subsection{Obtenção e Características do Efluente}

Ao término do processo de produção é gerado um efluente de cor verde amarelada com partículas em suspensão e com grande concentração de ácidos orgânicos utilizados como aditivos no processo. A geração deste efluente é de aproximadamente $3.000 \mathrm{~L} \mathrm{~d}^{-1}$. Foram coletadas amostras do efluente no período de 04/2016 a 11/2016. Essas amostras foram acondicionadas em bombas de $25 \mathrm{~L}$ previamente higienizadas e levadas ao Laboratório de Ciências Ambientais para serem utilizadas nos ensaios de tratabilidade. $O$ efluente bruto foi coletado e analisado em relação aos parâmetros $\mathrm{DQO}$, turbidez e pH. $\mathrm{Na}$ Tabela 1 pode-se observar os valores obtidos para os mesmos.

Tabela 1 - Valores dos parâmetros do efluente bruto

\begin{tabular}{cc}
\hline Parâmetros & Valores \\
DQO & $538-2168 \mathrm{mg} \mathrm{L}^{-1}$ \\
turbidez & $43-380 \mathrm{uT}$ \\
$\mathrm{pH}$ & $2,92-5,19$ \\
\hline
\end{tabular}

\subsection{Ensaio de Tratamento do Efluente em Sistema Contínuo}

No ensaio conduzido em sistema contínuo, foi utilizado um sistema de lodos ativados em escala de bancada, constituído por um reator biológico com volume de 3L, um decantador com volume de $1 \mathrm{~L}$ e o fornecimento de ar foi realizado por bombas difusoras. Um tanque com capacidade de armazenamento de $30 \mathrm{~L}$ de efluente foi acoplado a uma bomba peristáltica modelo Masterflex L/S (Cole Parmer), sendo esta responsável pela 
introdução do efluente bruto no sistema de lodos ativados com uma vazão de 4,2 $\mathrm{mL} \mathrm{min}^{-}$ 1, proporcionando um tempo de detenção hidráulica (TDH) de 12h. A Figura 1 mostra um esquema do sistema de lodos ativados utilizado no ensaio.

O tempo total de operação do sistema contínuo de lodos ativados foi de 24 dias. Todos os dias foram coletadas amostras para determinação dos parâmetros DQO, turbidez e pH no efluente bruto e no efluente tratado, além de uma amostra coletada no reator para determinação do parâmetro SST.

Figura 1- Esquema do sistema de lodos ativados utilizado no ensaio

Tanque de Alimentação

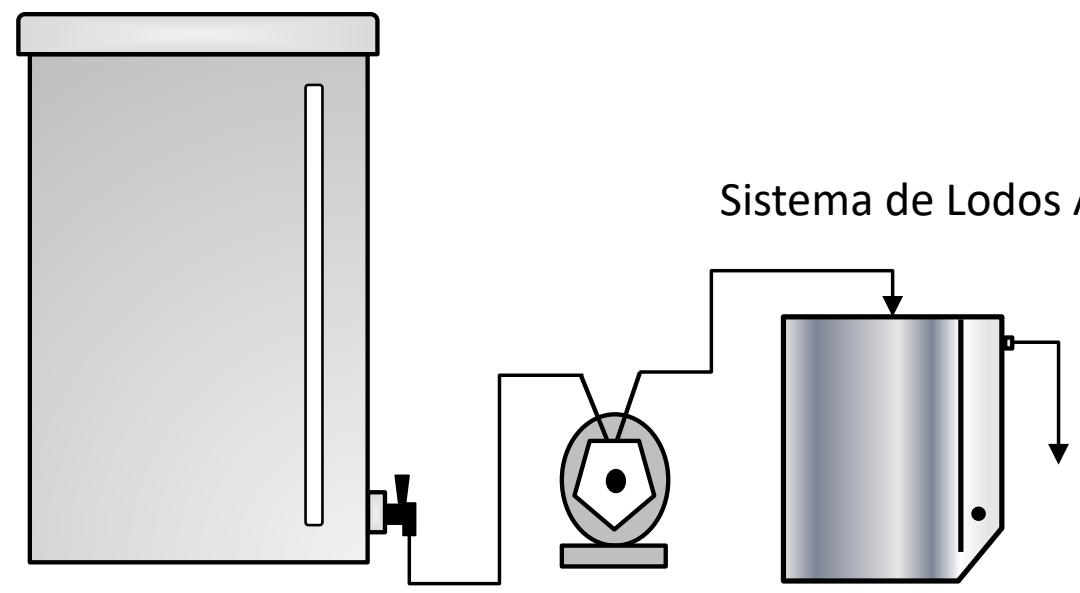

Bomba Peristáltica

\section{RESULTADOS E DISCUSSÃO}

\subsection{Decomposição da Matéria Orgânica (DQO)}

Na Figura 2 pode-se observar os valores de DQO no efluente final tratado e os percentuais de remoção de DQO durante os 24 dias de operação do sistema de lodos ativados. Nos primeiros 12 dias de operação, pode-se observar que houve uma forte variação de DQO no efluente final, oscilando entre os valores de $378 \mathrm{mg} \mathrm{L}^{-1}$ (4 $4^{\circ}$ dia) a 152 $\mathrm{mg} \mathrm{L}^{-1}\left(11^{\circ} \mathrm{dia}\right)$, correspondendo a percentuais de remoção de 82,5 a 87,8\%, respectivamente. A partir do $12^{\circ}$ dia tanto os valores de DQO do efluente final, quanto os percentuais de remoção mostram variações bem menores, apresentando valores na faixa de 112 a $32 \mathrm{mg} \mathrm{L}^{-1}$, correspondendo a remoções de 92,6 a 97,5\%, respectivamente. 
Figura 2 - Valores e percentuais de DQO no efluente final tratado

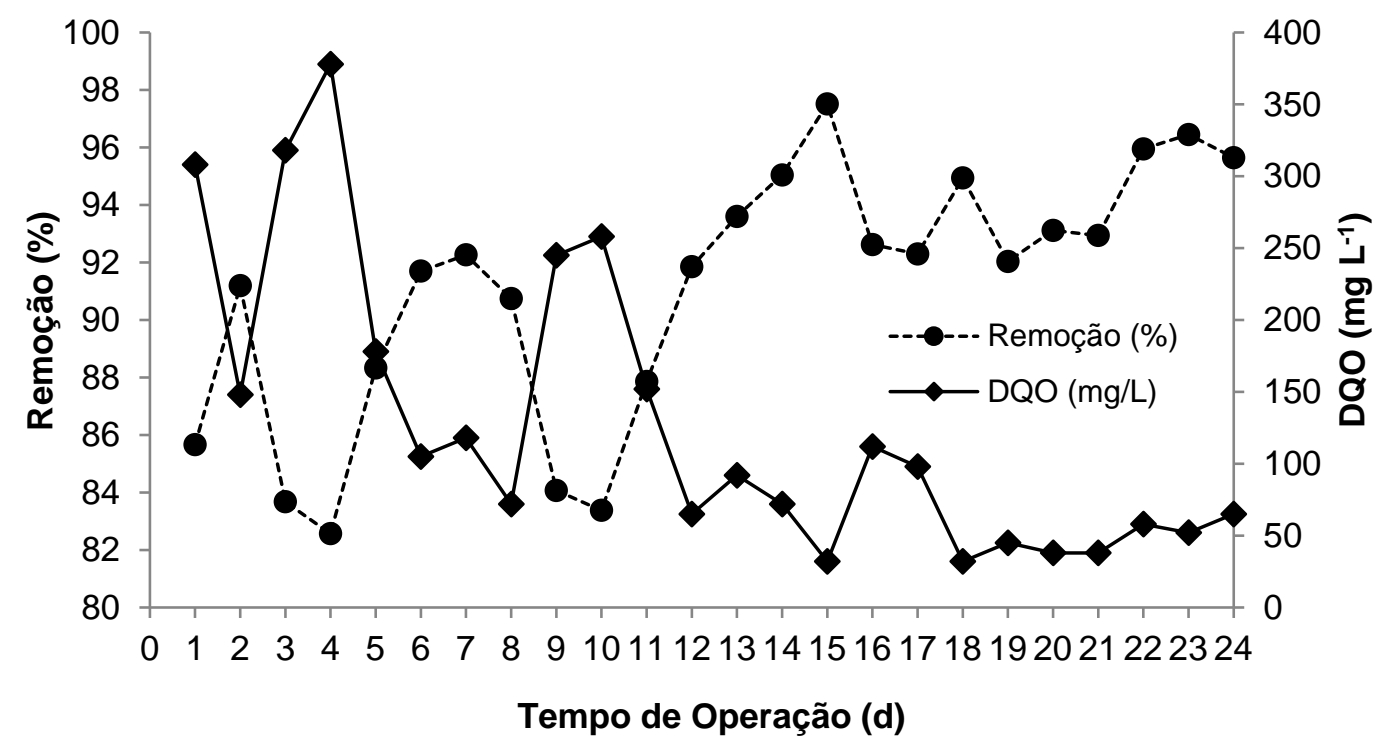

Segundo Von Sperling (2005), o sistema de lodos ativados apresenta remoção de DQO na ordem de 85 a 90\% (convencional) e de 90 a 95\% (aeração prolongada). Segundo a DZ-205, para efluentes de indústrias de alimentos, a DQO do efluente tratado deve ter uma concentração menor que $400 \mathrm{mg} \mathrm{L}^{-1}$. Nota-se que mesmo nos primeiros dias de operação, onde os valores de DQO do efluente foram mais elevados, estes se apresentaram dentro do limite estabelecido.

\subsection{Relação Alimento/Microrganismo (A/M)}

Uma relação amplamente utilizada pelos projetistas e operadores de estações de tratamento é a relação A/M. Tal baseia-se no conceito de que a quantidade de alimento ou substrato disponível por unidade de massa dos microrganismos é relacionada com a eficiência do sistema (Jordão e Pêssoa, 2011). Na Figura 3 pode-se observar a evolução da relação $A / M$ no ensaio em sistema contínuo de lodos ativados durante os 24 dias de operação. Foi ulizada uma relação SSVISST de 0,70 para estimativa dos valores de SSV no reator. 
Figura 3 - Valores da relação A/M no efluente final tratado

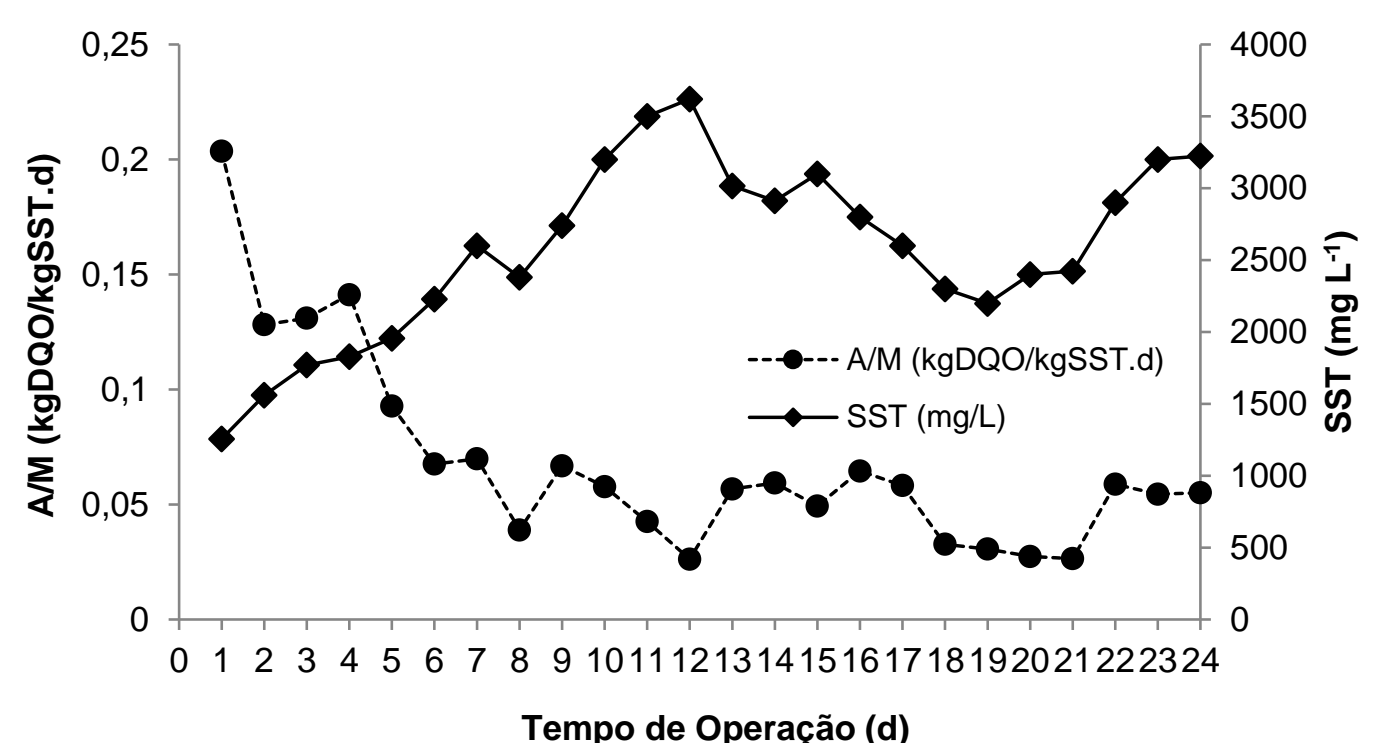

Como pode-se observar na Figura 3, a partir do $6^{\circ}$ dia de operação, a relação $A / M$ atingiu valores bem próximos aos recomendados para sistemas de lodos ativados aeração prolongada $(0,05$ a $0,15 \mathrm{kgDQO} / \mathrm{kgSSV} . \mathrm{d})$. A partir deste dia (6 $\left.6^{\circ} \mathrm{dia}\right)$, até o $24^{\circ}$ dia os valores obtidos permaneceram na faixa de 0,026 a 0,07 kgDQO/kgSSV.d. Segundo Von Sperling (2005) para uma baixa relação A/M, maior será a avidez pelo alimento, implicando numa maior eficiência na remoção do substrato.

Apesar dos valores da relação $A / M$ se aproximarem mais do sistema de lodos ativados aeração prolongada, os valores obtidos de SST aproximam-se mais da variante lodos ativados convencional (2000 a $4000 \mathrm{mg} \mathrm{L}^{-1}$ ). Do $6^{\circ}$ dia ao $24^{\circ}$ dia de operação, os valores permaneceram na faixa de 2198 a $3620 \mathrm{mg} \mathrm{L}^{-1}$.

\subsection{Comportamento da Turbidez no Efluente Final}

A turbidez não é usada como forma de controle do efluente de sistemas de lodos ativados, mas pode ser relacionada com a eficiência do tratamento (Jordão e Pessôa, 2011). Na Figura 4 pode-se observar os valores de turbidez no efluente final (saída do decantador) e os seus respectivos percentuais de remoção durante os 24 dias de operação do sistema de lodos ativados. 
Figura 4 - Valores de turbidez no efluente final tratado

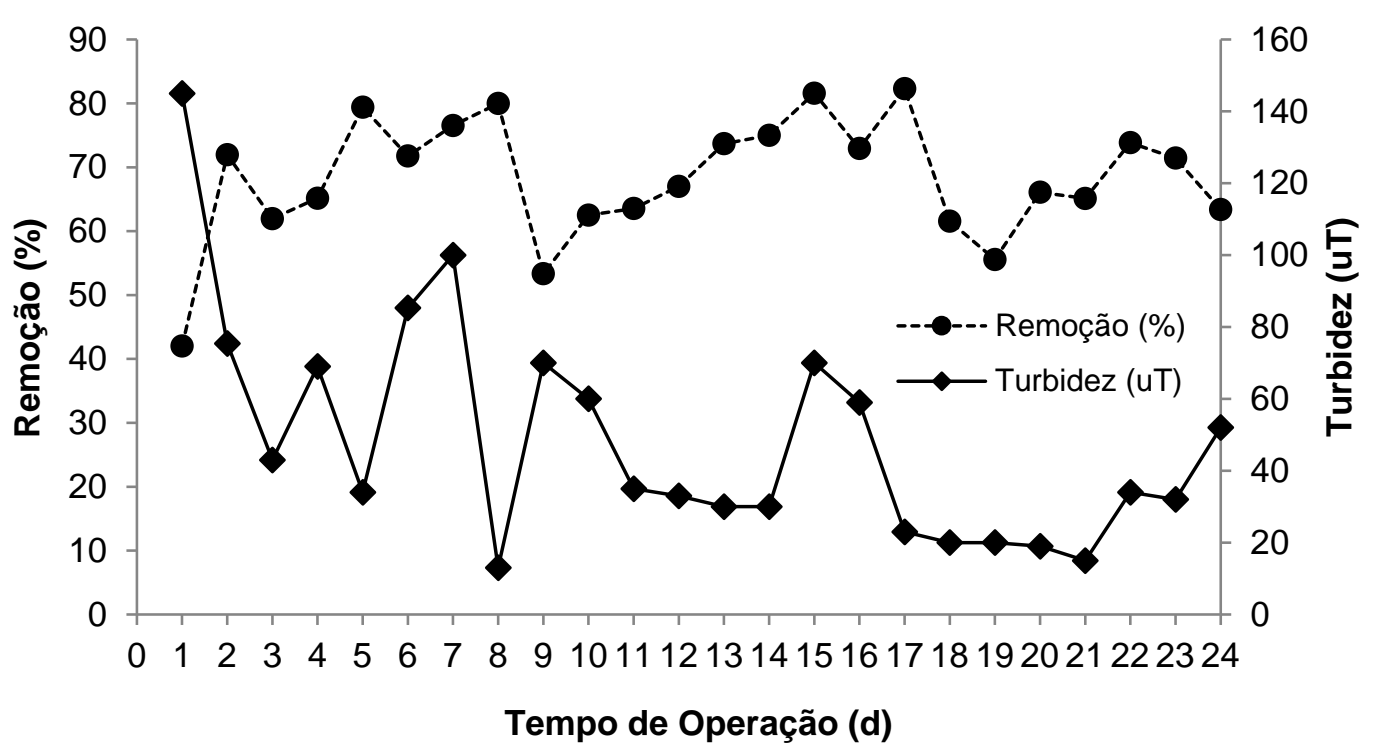

Pode-se observar na Figura 4 que os valores de turbidez no efluente tratado apresentou uma grande variação ao longo dos 24 dias de operação. No início do ensaio, os valores de turbidez oscilaram entre $145 \mathrm{uT}$, observado no $1^{\circ}$ dia ao valor de $13 \mathrm{uT}$ obtido no $8^{\circ}$ dia de operação. A partir do $8^{\circ}$ dia, as variações diminuem, obtendo valores na faixa de 15 a 70 uT até o $24^{\circ}$ dia, durante este intervalo, foram observados dois intervalos em que os valores de turbidez praticamente mantiveram-se constantes, do $10^{\circ}$ ao $14^{\circ}$ dia, e do $17^{\circ}$ ao $21^{\circ}$ dia.

Excetuando $01^{\circ}$ dia de operação, os percentuais de remoção de turbidez durante os demais 23 dias oscilaram na faixa de 50 a $82 \%$. As remoções mais expressivas foram observadas em dois intervalos de operação, do $5^{\circ}$ ao $8^{\circ}$ dia, apresentando remoções de 71,7 a $80 \%$, e do $15^{\circ}$ ao $19^{\circ}$ dia, correspondendo a remoções de 72,9 a $82,3 \%$.

Alguns autores descrevem que valores mais elevados de turbidez no efluente final podem estar relacionados a uma concentração maior de protozoários, uma vez que estes organismos não se agregam bem aos flocos e por isso, saem do sistema junto com o efluente final (Bento et al., 2005).

\subsection{Comportamento do pH no Sistema de Lodos Ativados}

Na Figura 5 pode-se observar que os valores de pH inicial mantêm-se na faixa ácida 
ao longo dos 24 dias de operação do sistema de lodos ativados. Segundo Von Sperling (1998) os valores de $\mathrm{pH}$ recomendados em geral para sistemas biológicos compreendemse entre 6,5 a 8,5 .

Figura 5 - Valores de $\mathrm{pH}$ no efluente final tratado

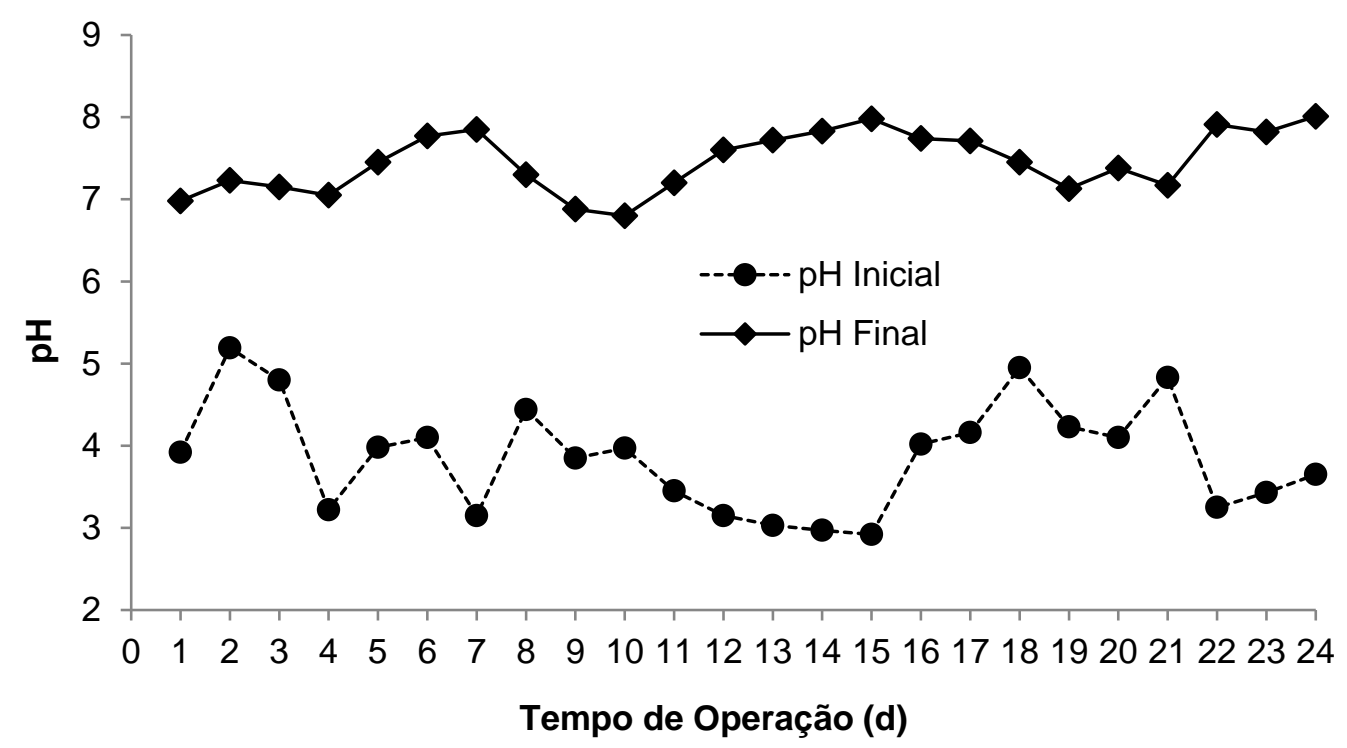

Como pode ser observado na Figura 5, os valores de $\mathrm{pH}$ inicial variaram entre os valores de 2,9 a 5,2. Este comportamento ácido deve-se a concentração elevada de ácidos como cítrico e ascórbico, além do metabissulfito de sódio utilizados no processo de fabricação das conservas de cogumelos. Como visto na Figura 5, o pH final teve seu valor elevado, mantendo-se na faixa de 6,8 a 8,0, muito próximo a faixa recomendada de operação.

Segundo alguns autores, mudanças bruscas de pH podem causar efeito tóxico para os microrganismos que são responsáveis pelo tratamento biológico, além de afetar as reações enzimáticas, diminuindo a velocidade das reações existentes no sistema (Claas, 2007; Filho, 2009). Como observado, aparentemente, esta mudança de faixa ácida para neutra e/ou levemente alcalina não contribuiu negativamente ao sistema, mostrando a capacidade de tamponamento do sistema de lodos ativados.

\section{CONCLUSÕES}

A partir dos resultados obtidos nos experimentos foi observada a eficiência do 
processo de lodos ativados no tratamento do efluente de indústria de cogumelo em conserva. Diante do monitoramento realizado durante os 24 dias de operação, foi possível uma eficiência de remoção de DQO > 90\%, de turbidez na faixa de 50 a 82\% e valores de $\mathrm{pH}$ no efluente final na faixa de 6,8 a 8,0. Segundo os resultados apresentados neste trabalho, o sistema mostra-se eficaz na remoção da matéria orgânica uma vez que a DZ205 preconiza uma remoção > 90\% e um pH final na faixa de 5,0 a 9,0 mantendo uma relação A/M de lodos ativados convencional (2000 a 4000 mg. $\mathrm{L}^{-1}$ ).

\section{REFERÊNCIAS}

BENTO, A.P.; SEZERINO, P.H.; PHILIPPI, L.S.; REGINATTO, V.; LAPOLLI, F.R. Caracterização da microfauna em estação de tratamento de esgotos do tipo lodos ativados: um instrumento de avaliação e controle do processo. Engenharia Sanitária e Ambiental, v. 10, n. 4, p. 329-338, out./dez. 2005.

BRASIL. Resolução $n^{\circ} \mathbf{4 3 0}$, de 13 de Maio de 2011- Dispõe sobre as condições e padrões de lançamento de efluentes, complementa e altera a Resolução n ${ }^{\circ}$ 357, de 17 de março de 2005, do Conselho Nacional do Meio Ambiente, Brasília, 9 p., 2011.

CLAAS, I.C. Lodos ativados: princípios teóricos fundamentais, operação e controle. Porto Alegre: Evangraf, 2007.

FILHO, H.A.S. Nitrificação em sistema de lodo ativado. Campina Grande, 2009. Dissertação (Mestrado em Engenharia de Recursos Hídricos e Sanitária) -Universidade de Federal de Campina Grande, 2009.

GIORDANO, G. Tratamento e controle de efluentes industriais - Apostila, 81 p., 2004.

INEA. Critérios e padrões para lançamento de efluentes líquidos. Rio de Janeiro, 4 p., 1986.

INEA. Diretriz de controle de carga orgânica em efluentes líquidos de origem industrial. Rio de Janeiro, 4 p., 1994.

JORDÃO, E.P.; PESSÔA, C.A. Tratamento de esgotos domésticos. 6. ed. Rio de Janeiro: ABES, 2011. $1050 p$

VAN HAANDEL, A.C., MARAIS, G.V.R. O Comportamento do sistema de lodo ativado: teoria e aplicações para projetos e operações. Campina Grande: Epgraf, 1999. 472 p.

VON SPERLING, M. Lodos ativados. 2. ed. Belo Horizonte, MG: UFMG, 2005. 428 p.

VON SPERLING, M. Introdução à qualidade das águas e ao tratamento de esgotos. Belo Horizonte, MG: UFMG, 1998. 243 p. 